\title{
APLICATIVO PARA ORIENTAÇÃO DE VÍTIMAS DE ACIDENTES COM ANIMAIS PEÇONHENTOS
}

\author{
Ângelo Leonardo Trovo Botelho de Lima ${ }^{1}$, Eduardo Guidugli Maria ${ }^{2}$, Guilherme Rocha \\ Donegá $^{1}$, Pedro Vitor Siqueira da Silva ${ }^{2}$, Edilson Carlos Caritá ${ }^{2}$
}

\section{Introdução}

Contemporaneamente, a sociedade utiliza a Tecnologia da Informação e Comunicação (TIC) para a realização das mais diferentes tarefas, principalmente, por meio de aplicativos instalados em dispositivos mobile. Os app tornaram-se ferramentas importantes na vida das pessoas. Portanto, é relevante que haja aplicativos que contemplem contextos de epidemiologia e saúde pública, que orientem a população sobre como se comportar em acidentes que podem ocorrer com o ser humano, inclusive aqueles que envolvem animais peçonhentos.

Vale destacar que, identificar o animal causador do acidente é muito importante para o tratamento de vítima picada por animais peçonhentos, viabilizar o recolhimento da espécie de importância médica em ambiente regional e auxiliar na indicação mais precisa dos antivenenos $^{\mathrm{i}}$, pois dependendo da espécie do animal, a pessoa acidentada pode vir a óbito caso não tenha o atendimento necessário ao acidente ocorrido.

O aplicativo denominado "Último Recurso" proporciona informações que visam orientar a população, de forma didática, quanto as ações que devem ocorrer após um acidente com animais peçonhentos, bem como auxiliar os profissionais da área da saúde nos procedimentos e cuidados, como por exemplo, qual soro antiofídico deve ser administrado, identificação de espécies distintas dos animais peçonhentos a partir de imagens e suas características, entre outras informações relevantes sobre esse contexto.

Para o desenvolvimento da proposta, foram utilizadas as bases de dados oficiais, através do acesso a ferramentas digitais e, o design gráfico do app foi criado com o uso das ferramentas Adobe Photoshop, Adobe Illustrator, Adobe After Effects e Adobe XD e o desenvolvimento deu-se com o uso do framework Android Studio e a linguagem de programação Flutter

\section{Breve apresentação do aplicativo}

A título de ilustração, elencamos a sequência das facetas do aplicativo, que se repete em cada categoria em cada categoria de incidente. Na Figura 1 é apresentada a tela inicial do app, com a logo do projeto e uma transição direta para a interface seguinte. Na Figura 2, há a primeira interface em que o usuário poderá escolher entre os acidentes ocorridos em humanos e/ou animais domésticos, a partir da escolha apresenta-se a terceira tela do app. Na Figura 3, o usuário encontra uma lista com os possíveis animais peçonhentos que podem provocar acidentes com humanos e/ou animais domésticos.

\footnotetext{
${ }^{1}$ Centro Universitário Barão de Mauá (CUBM) - Curso de Ciências Biológicas e Design Gráfico - Ribeirão Preto, SP - Brasil.

${ }^{2}$ Centro de Ciências Exatas, Naturais e Tecnologias - Curso de Engenharia de Software Universidade de Ribeirão Preto (UNAERP) - Ribeirão Preto, SP - Brasil Autores_correspondentes:_angelo.lima01@hotmail.com,_eduardo.guidugli@hotmail.com, guilhermedonega.gd@gmail.com pedrovitor.stz@hotmail.com, ecarita@unaerp.br
} 


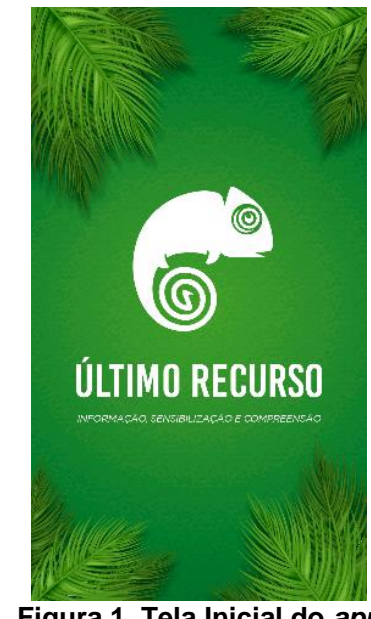

Figura 1. Tela Inicial do app
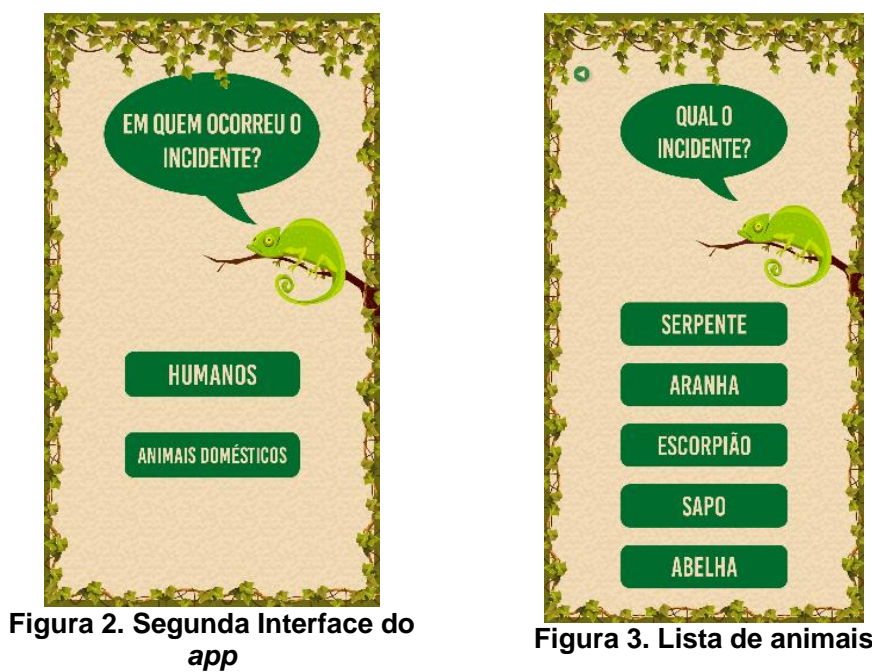

Figura 3. Lista de animais

Nas Figuras 4, 5 e 6, respectivamente, pode-se observar as espécies de animais peçonhentos, no caso, as aranhas e as informações do referido animal (qual o atendimento realizar em caso de acidente, as características da espécie, atividades da peçonha, curiosidades e os cuidados em caso de acidentes). A identificação da espécie será possível por meio das imagens disponibilizadas em um sistema de rolagem de fotos e de tela.

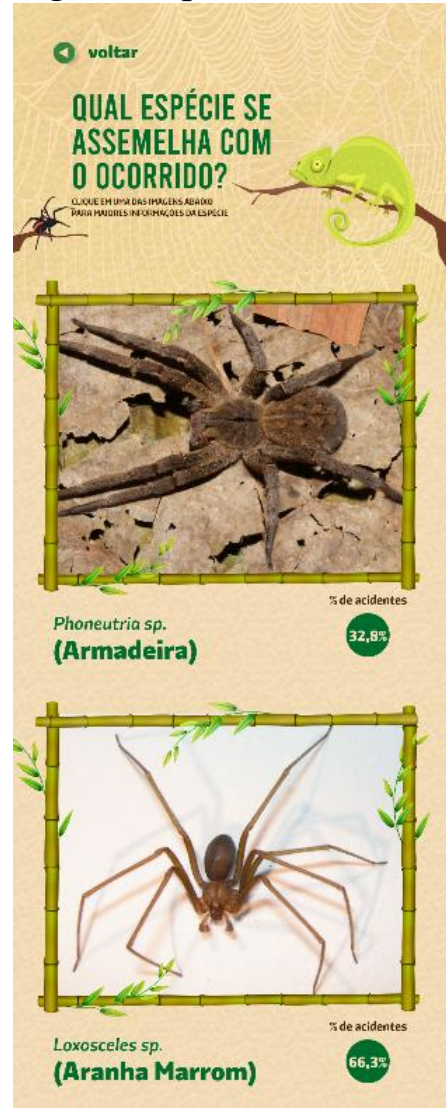

Figura 4. Fotos para auxiliar na identificação dos animais

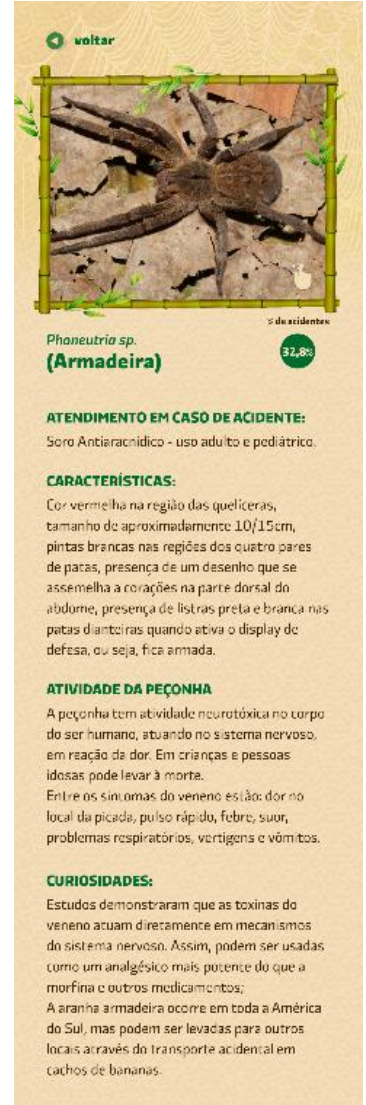

Figura 5. Informações sobre a aranha armadeira

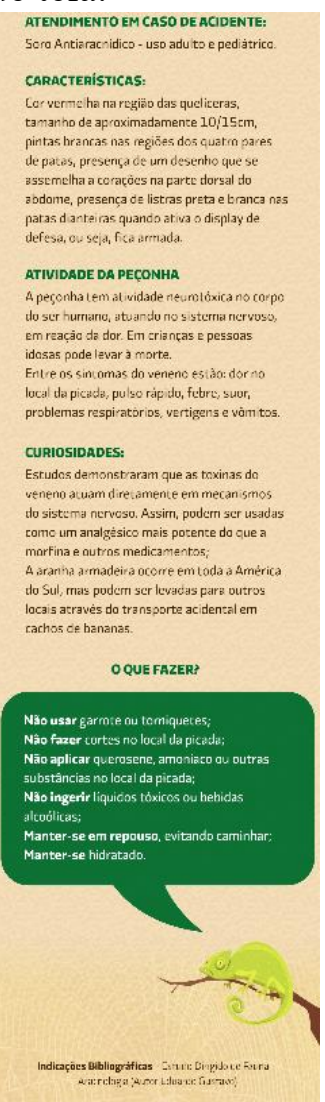

Figura 6. Informações sobre a aranha armadeira

${ }^{\text {i }}$ Brasil. Ministério da Saúde. Fundação Nacional de Saúde (2001) "Manual de diagnóstico e tratamento de acidentes por animais peçonhentos", 2 ed., Fundação Nacional de Saúde, Brasília. 